\title{
Optimization of a Method to Detect Autoantigen-Specific T-Cell Responses in Type 1 Diabetes
}

\author{
Yassmin Musthaffa ${ }^{1,2}$, Hendrik J. Nel ${ }^{2}$, Nishta Ramnoruth ${ }^{2}$, Swati Patel ${ }^{2}$, \\ Emma E. Hamilton-Williams ${ }^{2}$, Mark Harris ${ }^{1,2}$ and Ranjeny Thomas $^{2 *}$ \\ ${ }^{1}$ Department of Endocrinology and Diabetes, Queensland Children's Hospital, South Brisbane, QLD, Australia, \\ 2 The University of Queensland Diamantina Institute, The University of Queensland, Brisbane, QLD, Australia
}

OPEN ACCESS

Edited by:

Rudolf Valenta,

Medical University of Vienna, Austria

Reviewed by:

Willem Van Eden,

Utrecht University, Netherlands

Julia Eckl-Dorna,

Medical University of Vienna, Austria

*Correspondence:

Ranjeny Thomas

ranjeny.thomas@uq.edu.au

Specialty section:

This article was submitted to Antigen Presenting Cell Biology,

a section of the journal

Frontiers in Immunology

Received: 26 July 2020 Accepted: 02 November 2020 Published: 07 December 2020

Citation:

Musthaffa $Y, \mathrm{Nel} H J$, Ramnoruth N, Patel S, Hamilton-Williams EE, Harris M and Thomas R (2020) Optimization of a Method to Detect Autoantigen-Specific T-Cell Responses in Type 1 Diabetes.

Front. Immunol. 11:587469. doi: 10.3389/fimmu.2020.587469
The development of tolerizing therapies aiming to inactivate autoreactive effector T-cells is a promising therapeutic approach to control undesired autoimmune responses in human diseases such as Type 1 Diabetes (T1D). A critical issue is a lack of sensitive and reproducible methods to analyze antigen-specific T-cell responses, despite various attempts. We refined a proliferation assay using the fluorescent dye 5,6carboxylfluorescein diacetate succinimidyl ester (CFSE) to detect responding T-cells, highlighting the fundamental issues to be taken into consideration to monitor antigenspecific responses in patients with T1D. The critical elements that maximize detection of antigen-specific responses in T1D are reduction of blood storage time, standardization of gating parameters, titration of CFSE concentration, selecting the optimal CFSE staining duration and the duration of T-cell stimulation, and freezing in medium containing human serum. Optimization of these elements enables robust, reproducible application to longitudinal cohort studies or clinical trial samples in which antigen-specific T-cell responses are relevant, and adaptation to other autoimmune diseases.

Keywords: type 1 diabetes, proliferation, proinsulin, CD4+ T-cells, 5,6-carboxylfluorescein diacetate succinimidyl ester

\section{INTRODUCTION}

Type 1 Diabetes (T1D) is a chronic, incurable autoimmune disorder in which insulin-producing $\beta$-cells are selectively destroyed by islet-infiltrating T-cells $(1,2)$. The diagnosis of T1D is currently made at the onset of clinical symptoms. However, a long prodrome of autoimmune $\mathrm{T}$ and $\mathrm{B}$ cell activation leading to immune-mediated $\beta$-cell destruction precedes the onset of clinical diabetes. $\mathrm{CD}^{+}{ }^{+} \mathrm{T}$-cell responses are central to the pathogenesis of T1D (3-5) and several pathogenic selfepitopes have been reported. Human islet-infiltrating $\mathrm{CD} 4^{+} \mathrm{T}$-cell clones were shown to recognize epitopes from proinsulin-derived C-peptide, as well as neoantigens such as hybrid insulin peptides (HIPs) $(1,5,6)$. An important goal is the development of immunotherapies that prevent progression of $\beta$-cell destruction, thus intercepting T1D. Detecting and analyzing the function of islet-specific Tcells in humans has been challenging because of the low frequency of antigen-specific T-cells in the circulation and incomplete knowledge of their antigen specificity $(7,8)$. Consequently, there is currently an unmet need for a robust assay capable of tracking islet antigen-specific autoreactive 
T-cells to monitor immune-mediated activity while patients are undergoing immunotherapy. The desirable requirements of such an assay include 1) reliable performance with small blood volumes, 2) simplicity, 3) high sensitivity and specificity for detecting antigen specific T-cells in patients with or at-risk of $\mathrm{T} 1 \mathrm{D}, 4)$ reproducibility, and 5) applicability to frozen peripheral blood mononuclear cells (PBMCs) (9).

Fluorescent dye-based proliferation assays represent a popular method to monitor antigen-specific T-cell responses in vitro (10, 11). In these assays, PBMCs are labeled with a fluorescent dye, such as carboxyfluorescein diacetate succinimidyl ester (CFSE), and divide in response to antigenic stimuli. The resulting progeny retain half the number of CFSE molecules of its parent. The corresponding decrease in fluorescence intensity can be measured by flow cytometry and identifies proliferating cells. Dividing cells can also be phenotypically characterized using antibodies specific for surface markers and/or intracellular cytokines. CFSE is an ideal dye to measure cell division in view of its capacity to label lymphocyte populations with a high fluorescent intensity. It is also compatible with a broad range of other fluorochromes, thus allowing multi-color flow cytometry, and single-cell sorting to clone antigen-reactive T-cells (12). The primary limitations of flow cytometric dye-dilution assays relate to reproducibility, resulting from variable background proliferation in unstimulated wells, subjective gating, and inter-operator variability of up to $78 \%$ (13). Background proliferation decreases assay sensitivity, particularly with antigens that induce low levels of $\mathrm{T}$ cell proliferation, e.g., due to low precursor frequency in circulation or low affinity $\mathrm{T}$ cell receptors (TCRs). Autoreactive T-cells may also be more sensitive to apoptosis than other antigen-specific $\mathrm{T}$ cells (14). For example, low affinity interactions between a preproinsulin peptide and the Human Leucocyte antigen (HLA)-A2 molecule reduces binding affinity of the TCR-peptide-HLA complex, potentially enabling T-cells to escape thymic deletion and enter the periphery (15).

Here we optimized the sensitivity of a published CFSE-based T-cell proliferation assay that demonstrated proinsulin ${ }_{33-63^{-}}$ specific $\mathrm{CD}^{+} \mathrm{T}$ cells in patients with recent-onset T1D (16). We used PBMCs from children with T1D for less than 3 months, to systematically optimize assay parameters that contribute to either death of the responding antigen-specific T-cells or that increase background proliferation in the absence of added antigen. The described protocol results in a reproducible assay that can be replicated in other laboratories and adapted for monitoring in other autoimmune diseases.

\section{MATERIALS AND METHODS}

\section{Subjects}

Fresh blood (5-15 mls) was obtained from children (aged 2-16 years) with T1D duration of $\leq 3$ months after informed consent. Recruited individuals carried alleles associated with high risk of T1D (HLA DR3-DQ2, DR4-DQ8, or DR3-DQ2/DR4-DQ8) as previously described (16). The study was approved by the Children's Health Queensland, Mater Hospital, and University of Queensland Human Research Ethics Committees. T1D was defined according to the criteria from the American Diabetes Association (17).

\section{Cell Preparation}

PBMCs were isolated by Ficoll Density (GE Healthcare, Sweden) gradient centrifugation then washed twice in phosphate buffered saline. Islet antigen-specific $\mathrm{T}$-cell responses were measured using freshly isolated or thawed frozen PBMCs labeled with CFSE and cultured with or without islet peptides. Cells were cultured in complete medium [RPMI1640 medium, $1 \mathrm{U} / \mathrm{ml}$ penicillin/streptomycin/glutamate (Invitrogen, Thermo Fisher Scientific), $1 \mathrm{mM}$ sodium pyruvate (Gibco, Thermo Fisher Scientific)] supplemented with 5\% human serum (HS, Merck). Culture medium was filtered through a $0.2 \mu \mathrm{M}$ filter (Sartoriusminisart) prior to culture or washing steps. PBMCs from single patients were analyzed separately.

\section{Cell Freezing}

PBMCs were frozen at $10-25 \times 10^{6}$ cells/vial in $1.0 \mathrm{ml}$ of either $10 \% \mathrm{DMSO} /$ fetal bovine serum (FBS, heat inactivated, Life Technologies), $10 \% \mathrm{DMSO} / \mathrm{HS}$ or a commercial serum-free freezing medium (CTL Cryo ${ }^{\mathrm{TM}}$ ABC Media Kit, Immunospot, USA). Counted cells were initially resuspended in $0.5 \mathrm{ml}$ of either HS or CTL solution C and an equal volume of either $20 \%$ DMSO/FBS, 20\% DMSO/HS or CTL solution AB was added. The cell suspension was aliquoted into cryovials and placed in a "Mr Frosty" (Nalgene, Thermo Scientific, Denmark) containing iso-propanol, at $-80^{\circ} \mathrm{C}$ for $24-48 \mathrm{~h}$ before being transferred to liquid nitrogen.

Cells were thawed in a $37^{\circ} \mathrm{C}$ water-bath for $30 \mathrm{~s}$ and then added slowly to pre-warmed $5 \% \mathrm{HS} /$ complete media containing $12.5 \mu \mathrm{g} / \mathrm{ml}$ DNase I (Sigma). The cell suspension was centrifuged, and the supernatant discarded. Cells were then resuspended in pre-warmed 5\% HS/complete media supplemented with $6.25 \mu \mathrm{g} / \mathrm{ml}$ DNase I and rested for $30 \mathrm{~min}$ at $37^{\circ} \mathrm{C} 5 \% \mathrm{CO}_{2}$. The cell suspension was passed through a cell strainer to remove dead cell clumps, then centrifuged and resuspended in complete medium.

\section{Synthetic Antigens}

Tetanus toxoid (AJ Vaccines) was used at a concentration of 10 $\mathrm{Lf} / \mathrm{ml}$. Ultra-LEAF purified anti-human CD3 (Biolegend clone OKT3) was used at $0.1 \mu \mathrm{g} / \mathrm{ml}$. Proinsulin ${ }_{33-63}\left(\mathrm{PI}_{33-63}\right.$, Sequence: EAEDLQVGQVELGGGPGAGSLQPLALEGSLQ, GL Biochem), was initially reconstituted to $16.55 \mathrm{M}$ in DMSO (Sigma Aldrich) before making a working stock in PBS, of 2.5-5.0 mM for use at a final concentration of $10 \mu \mathrm{M}$ as previously reported to reliably induce $\mathrm{CD}^{+} \mathrm{T}$ cell proliferation (16).

\section{CFSE Staining and T-Cell Stimulation}

We followed methods previously described for a CFSE-based Tcell proliferation assay $(5,10)$ to measure antigen-specific CD $4^{+}$ T-cell proliferation to $\mathrm{PI}_{33-63}$. Briefly, a total of $10-20 \times 10^{6}$ PBMCs were re-suspended at $1 \times 10^{6}$ cells $/ \mathrm{ml}$ in pre-warmed $\left(37^{\circ} \mathrm{C}\right) 1 \mathrm{XPBS}$ before staining with CFSE dye (CellTrace ${ }^{\mathrm{TM}}$ CFSE Cell Proliferation Kit for flow cytometry, Invitrogen, Thermo 
Fisher Scientific). CFSE concentration and staining times are as indicated in the figure legends. The CFSE labeling reaction was terminated with pre-warmed, filtered complete media containing $2.5 \%$ HS. The cells were washed and then re-suspended at a concentration of $2 \times 10^{6} \mathrm{PBMCs} / \mathrm{ml}$ in pre-warmed, filtered $5 \%$ HS/RPMI. CFSE-stained cells $(200 \mu \mathrm{l}$ per well) were cultured in 96-well round bottom plates (Costar) for the number of days indicated in the figure legends, in $37^{\circ} \mathrm{C} 5 \% \mathrm{CO}_{2}$ with medium alone (negative control) or with $\mathrm{PI}_{33-63}$, or with positive controls, tetanus toxoid and/or anti-CD3. In most experiments, cells were cultured in triplicate for each condition. Unstained cells were included in all cultures and used as single color stained controls to determine compensation settings on the flow cytometer.

\section{Flow Cytometry Analysis}

After culture, triplicate wells were pooled, washed in saline and stained on ice with the following antibodies: anti-human CD3APC/Cy7 (Mouse IgG1, $\kappa$, clone UCHT1), anti-human CD4-PE/ Cy7 Antibody (Mouse IgG2b, $\kappa$, clone OKT4) and anti-human CD8a-Pacific Blue ${ }^{\mathrm{TM}}$ Antibody (Mouse IgG1, $\kappa$, clone HIT8a) (all from Biolegend, San Diego, CA). Gating of the major T cell populations was set using Fluorescence minus one (FMO) controls. LIVE/DEAD ${ }^{\mathrm{TM}}$ Fixable Aqua Dead Cell Stain Kit (Invitrogen, Thermo Fisher Scientific) was used to exclude dead cells. Harvested cells were acquired on a Gallios flow cytometer (Beckman Coulter) and analyzed with Kaluza software (Version 2.1, Beckman Coulter). Optimal voltage settings were determined for each experiment based on unstained and single stained samples. Viable $\mathrm{CD} 3^{+} \mathrm{CD} 4^{+}$ lymphocytes were gated. We acquired at least $2 \times 10^{5}$ lymphocytes in order to identify 5,000 $\mathrm{CD}^{+} \mathrm{CFSE}^{\text {(undivided) }}$ cell events. The results are presented as a cell division index (CDI), the ratio of $\mathrm{CD} 4^{+} \mathrm{T}$-cells that proliferated in response to antigen, relative to cells that proliferated in absence of antigen $(10,16)$. The CDI was calculated based on a fixed number of $5,000 \mathrm{CD}^{+} \mathrm{CFSE}^{\text {(undivided) }}$ cells using the following formula:

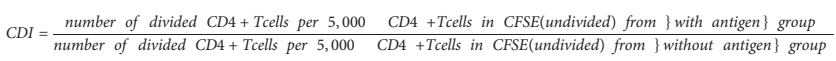

A CDI of $\geq 3$ was considered to represent the threshold for the positive control responses (16). Data from CFSE-based T-cell proliferation assays in which the CDI for both positive control antigen(s) did not exceed 3.0 were excluded from the analysis.

\section{VPD-450 Staining}

Freshly isolated PBMCs $\left(10-20 \times 10^{6}\right)$ were labeled with BD Horizon ${ }^{\text {TM }}$ Violet Proliferation Dye $450(\mathrm{VPD} 450)$ at $10 \times 10^{6}$ cells/ml in pre-warmed PBS with the concentrations of VPD450 as indicated. After $15 \mathrm{~min}$ the reaction was terminated with pre warmed 5\% HS/complete medium. After washing, PBMC were resuspended to $2 \times 10^{6} / \mathrm{ml}$ in pre-warmed, filtered $5 \% \mathrm{HS}$ / complete medium.

\section{Assay Qualification}

To determine the precision and reproducibility of the CFSE-based $\mathrm{T}$-cell proliferation assay, we produced a standard operating procedure $(\mathrm{SOP})$ and measured $\mathrm{CD}^{+} \mathrm{T}$-cell responses to $\mathrm{PI}_{33-63}$ and tetanus toxoid from cryopreserved PBMC of a single patient diagnosed with $\mathrm{T} 1 \mathrm{D} \leq 3$ months. We qualified the assay as fit-for purpose for research environments and non-regulated laboratories per recent guidelines for flow cytometry assays (18). Two analysts conducted independent experiments from the same sample. In each assay, six wells were set up for each condition. After 7 days of incubation, two wells were pooled together and analyzed as a single sample, resulting in three replicates. CDI values were calculated either from each replicate or using mean value of replicates of unstimulated cells to calculate CDI of stimulated cells. We calculated mean, standard deviation (SD), and coefficient of variation $(\mathrm{CV})$ to provide intra-assay precision (\%CV of CDI values from replicates of each condition), repeatability (mean \%CV from assays of independent analysts) and inter-assay reproducibility (combined $\% \mathrm{CV}$ from assays of independent analysts).

\section{STATISTICAL ANALYSIS}

Pair-wise comparison between categorical variables was conducted with the Chi-square test, or the Fisher's exact test if one or more cells in the contingency table had an expected frequency of $\leq 5$ using Graphpad Prism (Version 7, San Diego, CA, USA) and R Statistical Software (Version 3.5.3, Foundation for Statistical Computing, Vienna, Austria). The Kruskal-Wallis test was used for multiple comparisons, followed by post-hoc Dunn's Test (1964) and p-values were adjusted with the Benjamini-Hochberg method. Comparisons between group data were made using the paired two-tailed t-test. Statistical significance was defined as $\mathrm{p}<0.05$.

\section{RESULTS}

\section{Standardization of Gating Parameters}

To optimize a CFSE-based T-cell proliferation assay for detection of $\mathrm{PI}_{33-63}$ specific $\mathrm{CD}^{+} \mathrm{T}$ cells, CFSE-labeled freshly isolated PBMC from subjects with recent-onset T1D were stimulated for 7 days with or without $\mathrm{PI}_{33-63}$ or anti-CD3 as a positive control. We then standardized gating parameters in several stages, aiming to create an objective gating strategy, but reducing background proliferation in the no-peptide wells to a minimum. After setting a gate around the CFSE ${ }^{\text {(undivided) }}$ population to include all undivided cells, parameters for the borders of the $\mathrm{CFSE}^{\text {(divided) }}$ gate were calculated mathematically based on the Mean Fluorescence Intensity (MFI) of the CFSE ${ }^{\text {(undivided) }}$ population. The top and left border of the CFSE ${ }^{\text {(divided) }}$ gate was set at the top and left edge of the plot, respectively. The right-hand border of the $\mathrm{CFSE}^{\text {(divided) }}$ gate was calculated based on the fluorescence intensity of CFSE stained cells halving with each cell division. The right-hand border of the $\mathrm{CFSE}^{\text {(divided) }}$ gate was set at 3 cell divisions (MFI (undivided) $/ 2^{3}$ ) for the first and second revisions. The lower border of the CFSE ${ }^{\text {(divided) }}$ was raised to align with the lower border of the $\mathrm{CFSE}^{\text {(undivided) }}$ population. In order to capture antigen-specific proliferation while reducing the capture of background proliferation of no-peptide wells, the 


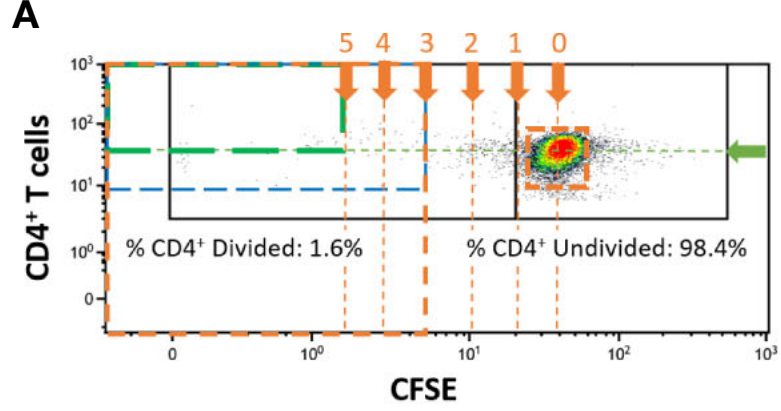

C

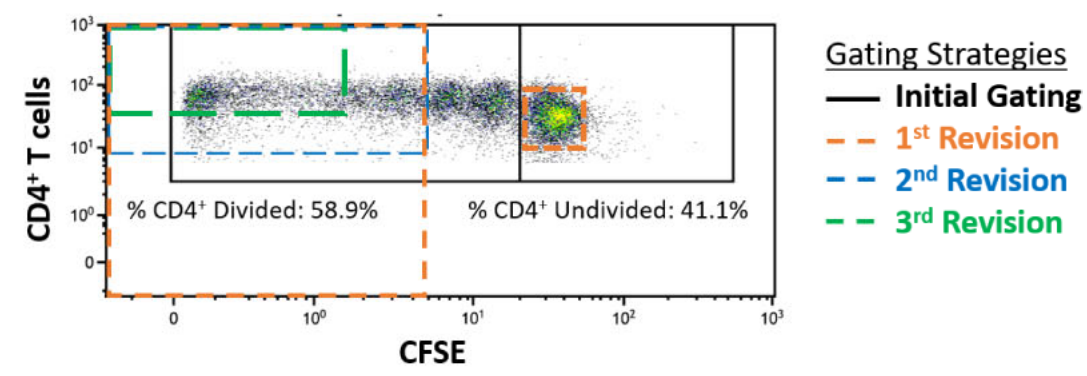

B
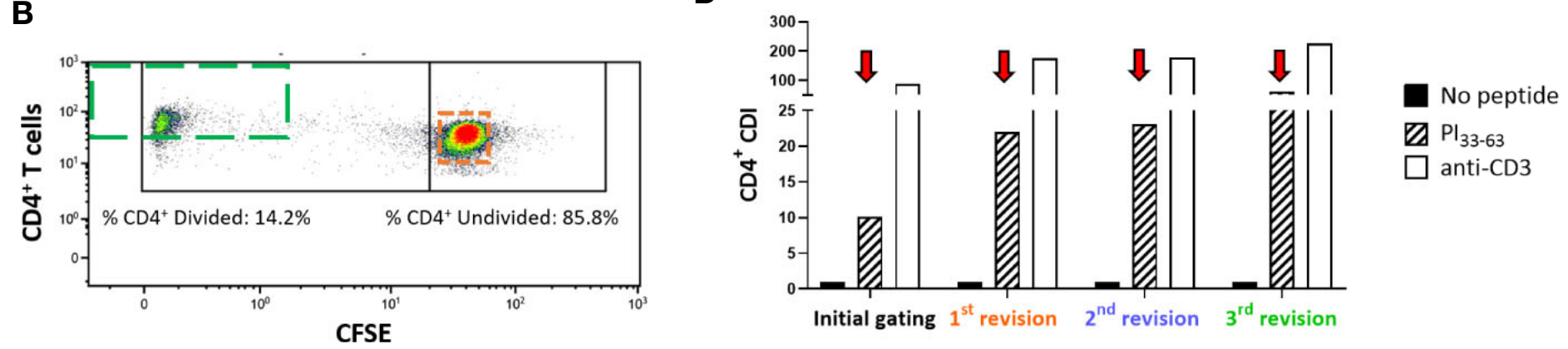

FIGURE 1 | Representative flow cytometry plots displaying gating strategies to assess CD4 ${ }^{+}$T-cell proliferative responses in freshly isolated PBMC measured with the CFSE proliferation assay after a 7-day incubation. Cells were first gated on $\mathrm{CD}^{+} \mathrm{CD}^{+}$live single cells. (A) PBMC that were incubated without antigen (no-peptide negative control), (B) PBMC incubated with $\mathrm{Pl}_{33-63}$, (C) PBMC incubated with anti-CD3 (positive control). Proliferating cells are gated (left gates). In this example, $14.21 \%$ of $\mathrm{CD}_{4}^{+} \mathrm{T}$-cells divided in response to incubation with $\mathrm{Pl}_{33-63}$ when the $3^{\text {rd }}$ revised gating strategy was applied. Gates are set mathematically on the no-peptide condition and applied to all other conditions. The "initial gating" capturing the CFSE ${ }^{\text {(undivided) }}$ cells on the right, and CFSE(divided) $c e l l s$ on the left is shown in black. The arrows labeled " $0,1,2,3,4,5$ " indicate the numbers of cell divisions, equivalent to MFI divided by 1, 2, 4, 8, 16, 32. The green arrow indicates the MFI of CD4, expressed by the CFSE (undivided) population. (D) Revised gating strategies reduced capture of the no-peptide background proliferation and resulted in a higher CDI for all antigen-stimulated conditions. CDI, Cell division index. 
right-hand border of the $\mathrm{CFSE}^{\text {(divided) }}$ gate was set at 5 cell divisions (MFI ${ }^{\text {(undivided) }} / 2^{5}$ ) and the bottom border position was objectively set at the MFI of the $\mathrm{CD}^{+}$staining of the CFSE ${ }^{\text {(undivided) }}$ population for the third revision (Figures 1AC). Each gating revision decreased the number of events within the no-peptide divided cell gate and correspondingly increased the discrimination of the $\mathrm{PI}_{33-63}$ stimulated cells and CDI (Figure 1D).

\section{Titration of CFSE Concentration}

CFSE is toxic at high concentrations and with prolonged cell exposure. We therefore titrated the CFSE labeling concentration and then assessed proinsulin-specific proliferative responses. PBMC were stained with varying concentrations of CFSE, then cultured with or without $\mathrm{PI}_{33-63}$, tetanus toxoid or anti-CD3 for 7 days (Supplementary Figure 1). The intensity of CFSE staining and the percentage of dead cells decreased as the CFSE labeling concentration decreased (Figure 2). A CFSE concentration of $<0.025 \mu \mathrm{M}$ was insufficient to detect dividing $\mathrm{PI}_{33-63}$, tetanus toxoid or anti-CD3-stimulated cells. A CFSE labeling concentration of $0.05 \mu \mathrm{M}$ achieved the highest CDI and the best balance between CFSE staining intensity and $\mathrm{PI}_{33-63}$-specific proliferation (Figure 2).

\section{CFSE Staining Time}

We next determined whether shortening CFSE staining duration would reduce toxicity. Freshly isolated PBMC were stained with $0.05 \mu \mathrm{M}$ CFSE for 5 or $10 \mathrm{~min}$ before the CFSE reaction was terminated. PBMC were subsequently cultured with or without $\mathrm{PI}_{33-63}$, tetanus toxoid or anti-CD3 for 7 days (Figure 3 and Supplementary Figure 2). A single analyst performed technical replicates on three patients with $\mathrm{T} 1 \mathrm{D} \leq 3$ months. The percentage of live cells decreased, and intensity of CFSE staining and background proliferation increased with longer duration of CFSE staining. Staining for $5 \mathrm{~min}$ still resulted in sufficiently bright CFSE staining to discriminate divided and undivided cell populations (Supplementary Figure 2). CFSE staining time of $5 \mathrm{~min}$, which resulted in the highest CDI, was selected to provide the best balance between cell death, background proliferation, and antigen-specific proliferation.

\section{Time Course of PBMC Proliferation}

To determine the number of days in culture for optimal $\mathrm{PI}_{33-63-}$ specific proliferation, CFSE-stained fresh PBMCs were cultured with medium alone, $\mathrm{PI}_{33-63}$, tetanus toxoid or anti-CD3 for 4, 5, $7,9,10$, or 11 days. A single analyst performed technical replicates on five patients with $\mathrm{T} 1 \mathrm{D} \leq 3$ months. With culture durations $>7$ days, antigen-specific proliferation did not change, but background proliferation in the absence of antigen increased, thus reducing the CDI (Figure 4). In cultures harvested earlier than 7 days, antigen-specific proliferation was reduced. The CDI was greatest at 7 days of culture (Day 4 vs. Day 7, $\mathrm{p}=0.023$; Day 5 vs. Day 7, p = 0.015; Day 7 vs. Day 9, ns; Day 7 vs. Day 10, p = 0.079; Day 7 vs. Day 11, p = 0.011). Day 7 was therefore selected in subsequent experiments as the optimal time to assess antigen specific proliferation.

\section{Comparison of Freshly Isolated and Frozen PBMC in the CFSE-Based T-Cell Proliferation Assay}

T-cell proliferation assays would ideally measure responses in longitudinal studies or clinical trial samples in which frozen specimens from one patient would be compared at all time points in one run. $\mathrm{CD} 4^{+} \mathrm{T}$ responses to $\mathrm{PI}_{33-63}$, tetanus toxoid and human anti-CD3 were compared after cryopreservation in commonly used freezing media supplemented with Fetal Bovine Serum (FBS), Human Serum (HS), or serum-free media (CTL Cryo ${ }^{\mathrm{TM}}$ solution ABC) in eight separate patients (Figure 5). Five patients had T1D $\leq 3$ months and three patients had T1D > 3 months. There was a significant decrease in $\mathrm{CD}^{+} \mathrm{T}$-cell proliferative responses when cells were frozen in FBS and CTL Cryo $^{\mathrm{TM}}$ solution compared to that detected with freshly isolated PBMC ( $p=0.016$ and 0.014 , respectively). PBMCs cryopreserved in $\mathrm{HS} / 10 \%$ DMSO produced the lowest number of background events (Supplementary Figure 3) of all freezing media tested, and no sample was excluded based on positive control CDI $\leq 3$. Based on tetanus toxoid-specific CDI $\leq 3$ using PBMCs cryopreserved with $\mathrm{CTL} \mathrm{Cryo}^{\mathrm{TM}}$ solution or FBS, one or two samples respectively would have been excluded. We conclude that $\mathrm{CDI}$ of $\mathrm{PI}_{33-63}-$ specific assays conducted after freezing cells in HS/10\% DMSO and thaw did not differ from CDI for the same assays conducted fresh (Figure 5).

\section{VPD450-Based T-Cell Proliferation Assay}

\section{Dose Titration}

As CFSE was cytotoxic at high labeling concentrations or with prolonged labeling, we compared CFSE with an alternative membrane dye, VPD450 (19). Freshly isolated PBMCs were labeled with varying concentrations of VPD450 for $15 \mathrm{~min}$ as recommended by the manufacturer and cultured for 7 days. At a VPD450 concentration of $0.1 \mu \mathrm{M}$, background proliferation of the no-peptide control was much higher than for the CFSE no-peptide control, and similar to the $\mathrm{PI}_{33-63}$-specific response (Figure 6A). VPD450 $>0.5 \mu \mathrm{M}$ increased labeling intensity but reduced both \% live cells and \% divided cells after culture (Supplementary Figure 4). Tetanus Toxoid-specific $\mathrm{CD} 4^{+} \mathrm{T}$-cell proliferation was maximal at $0.25 \mu \mathrm{M}$ VPD450 and this concentration was selected to provide the best balance between staining intensity and CDI.

\section{Comparison of CFSE-Based or VPD450-Based Proliferation Assay for CD4 ${ }^{+} \mathrm{T}$-Cell Proliferation}

T-cell responses to $\mathrm{PI}_{33-63}$, tetanus toxoid and anti-CD3 were compared using a CFSE-based or VPD450-based T-cell proliferation assay in freshly isolated PBMCs obtained from each of 10 patients with T1D of $\leq 3$ months duration. Notably, VPD450 increased background proliferation in the absence of antigen, which reduced the antigen-specific CDI (Figure 6B). No samples were excluded based on positive control CDI $\leq 3$. $\mathrm{PI}_{33-63-}$ specific proliferative responses detected with CFSE were of a significantly greater magnitude than those with $\operatorname{VPD}(p=0.0412)$.

\section{Sample Storage Time Prior to Processing}

We determined whether the time from venepuncture to isolation of PBMCs from freshly isolated blood affected CDI in 3 patients 

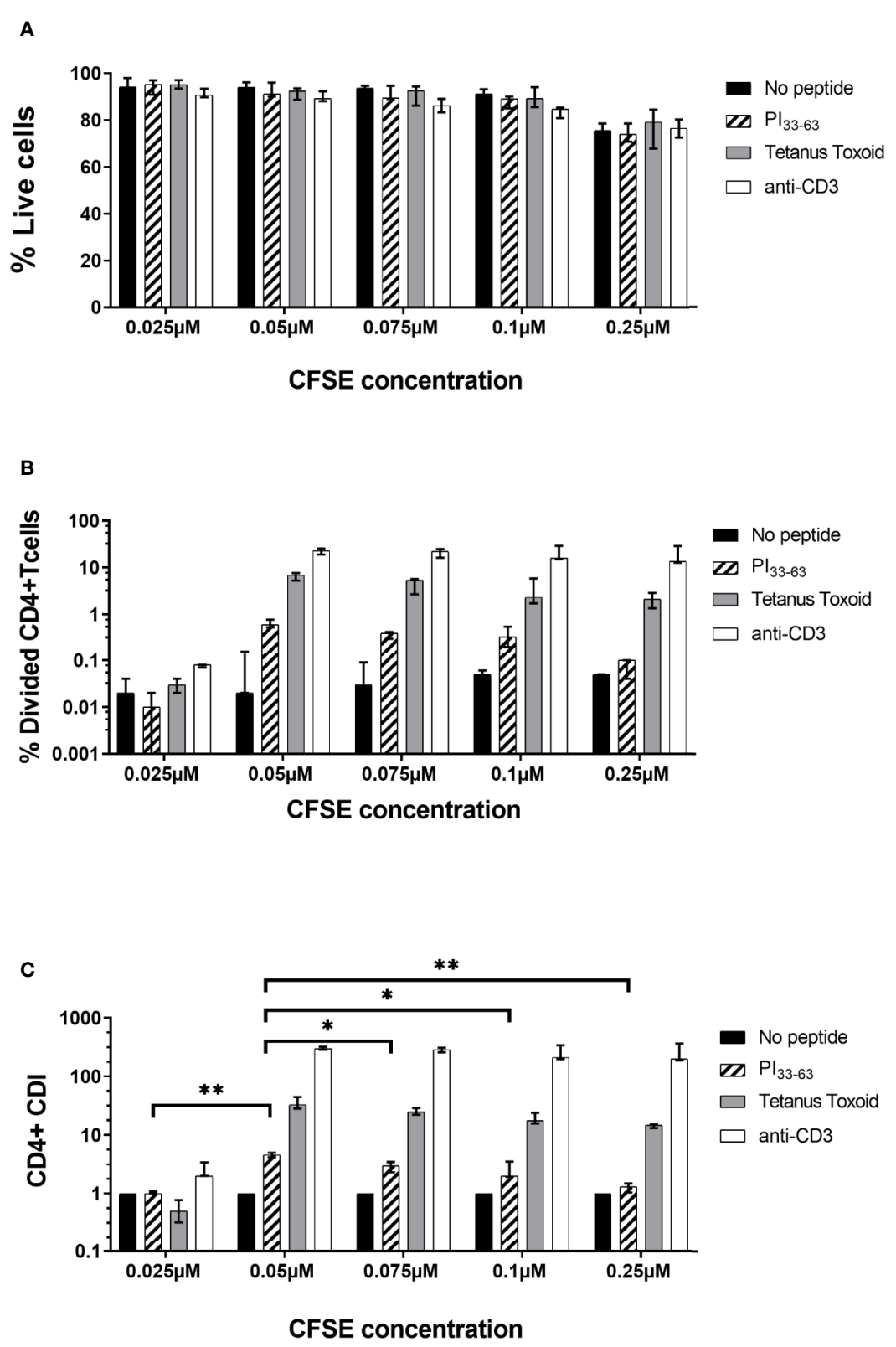

FIGURE 2 | Titration of CFSE concentration. Freshly isolated PBMC from three patients were stained with different concentrations of CFSE as shown and incubated with $\mathrm{Pl}_{33-63}(10 \mu \mathrm{M})$, tetanus toxoid $(10 \mathrm{Lf} / \mathrm{ml})$ or anti-CD3 antibodies $(0.1 \mu \mathrm{g} / \mathrm{ml})$ for 7 days. (A) Percentage of live cells after 7 days of incubation. (B) Percentage of Divided CD4 ${ }^{+}$T-cells. (C) CD4 ${ }^{+}$T-cell Division Index. Median value and range from three technical replicates are shown. CDI for each CFSE concentration was compared: ${ }^{*} p<0.05,{ }^{* *} p<0.01$, paired t test.

with T1D $\leq 3$ months. Each patient's sample was processed at three different timepoints; within 4 h, 12-16 h, or 22-24 h after collection (Supplementary Figure 5). Samples were stored at room temperature on a benchtop shaker. Cell viability decreased and $\mathrm{CD} 4^{+} \mathrm{T}$-cell proliferation in no-peptide controls increased with longer storage time, resulting in a reduction in antigenspecific CDI. A blood storage time of $4 \mathrm{~h}$ or less optimized viability of $\mathrm{CDI}$.

\section{Intra-Assay Repeatability and Inter-Assay Reproducibility \\ $\mathrm{CD}^{+} \mathrm{T}$-Cell Proliferation}

To assess reproducibility, we produced a SOP for the assay and a qualification plan, and measured $\mathrm{CD}^{+}$T-cell responses to $\mathrm{PI}_{33-63}$ and tetanus toxoid from cryopreserved PBMC of a single patient diagnosed with $\mathrm{T} 1 \mathrm{D} \leq 3$ months. Two analysts conducted independent experiments from the same sample. In 


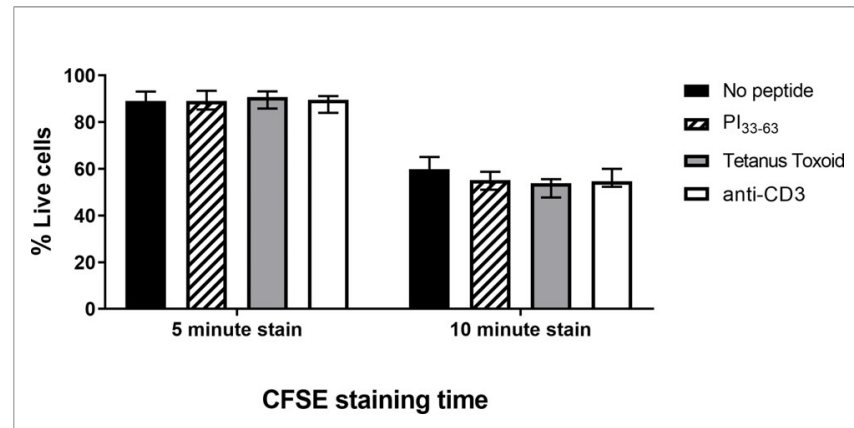

FIGURE 3 | The influence of CFSE staining time on percentage of live cells after 7 days of incubation. Freshly isolated PBMC were stained with CFSE $(0.05 \mu \mathrm{M})$ for 5 or 10 min and incubated with $\mathrm{Pl}_{33-63}(10 \mu \mathrm{M})$, tetanus toxoid (10 Lf/ml), or anti-CD3 antibodies $(0.1 \mu \mathrm{g} / \mathrm{ml})$ for 7 days. Median value and range from three technical replicates are shown.

each assay, six wells were set up for each condition. After culture with or without antigens, two wells were pooled together and analyzed as a single sample, resulting in three replicates. CDI were calculated from each replicate, or using mean value of replicates, of no-peptide wells. The intra-assay precision \% $\mathrm{CV}$ was $52.82 \%$ for $\mathrm{PI}_{33-63}$-stimulated cells when CDI was calculated from each individual replicate of unstimulated cells. We found that small differences in the numbers of proliferating cells within the no-peptide control wells introduced large variations in CDI values. To minimize this variability, we used the mean value of no-peptide control triplicates to calculate antigen-specific CDI. This improved the overall precision outcome, including precision for $\mathrm{PI}_{33-63}$-stimulated cells to $29.73 \% \mathrm{CV}$, to within an acceptable level (Figure 7). The intra-assay repeatability was also within the recommended limit of CV $\leq 35 \%$ (18) when CDI values were calculated using the mean value of no-peptide control triplicates. Inter-assay reproducibility was within recommended limits for $\mathrm{PI}_{33-63}$ (18), but not for tetanus toxoid when calculating CDI values using the mean of replicates of nopeptide controls. Thus, it is recommended 1) that conditions are assayed in triplicate, preferably first pooling wells, to determine the mean value of no-peptide control replicates, and 2) that for time-point comparisons, one analyst runs all samples from a donor simultaneously in one assay.

To assess precision in a larger group of patients, one analyst measured CD4 ${ }^{+}$T-cell responses to $\mathrm{PI}_{33-63}$ and tetanus toxoid from freshly isolated PBMCs of five patients diagnosed with T1D $\leq 3$ months (Figure 8). Intra-assay precision was within the recommended limit of $\mathrm{CV} \leq 35 \%$ (18) for $\mathrm{PI}_{33-63}$-stimulated cells. When CDI values were calculated using the mean value of replicates of no-peptide controls, the intra-assay precision for tetanus toxoid-stimulated cells was within an acceptable level.

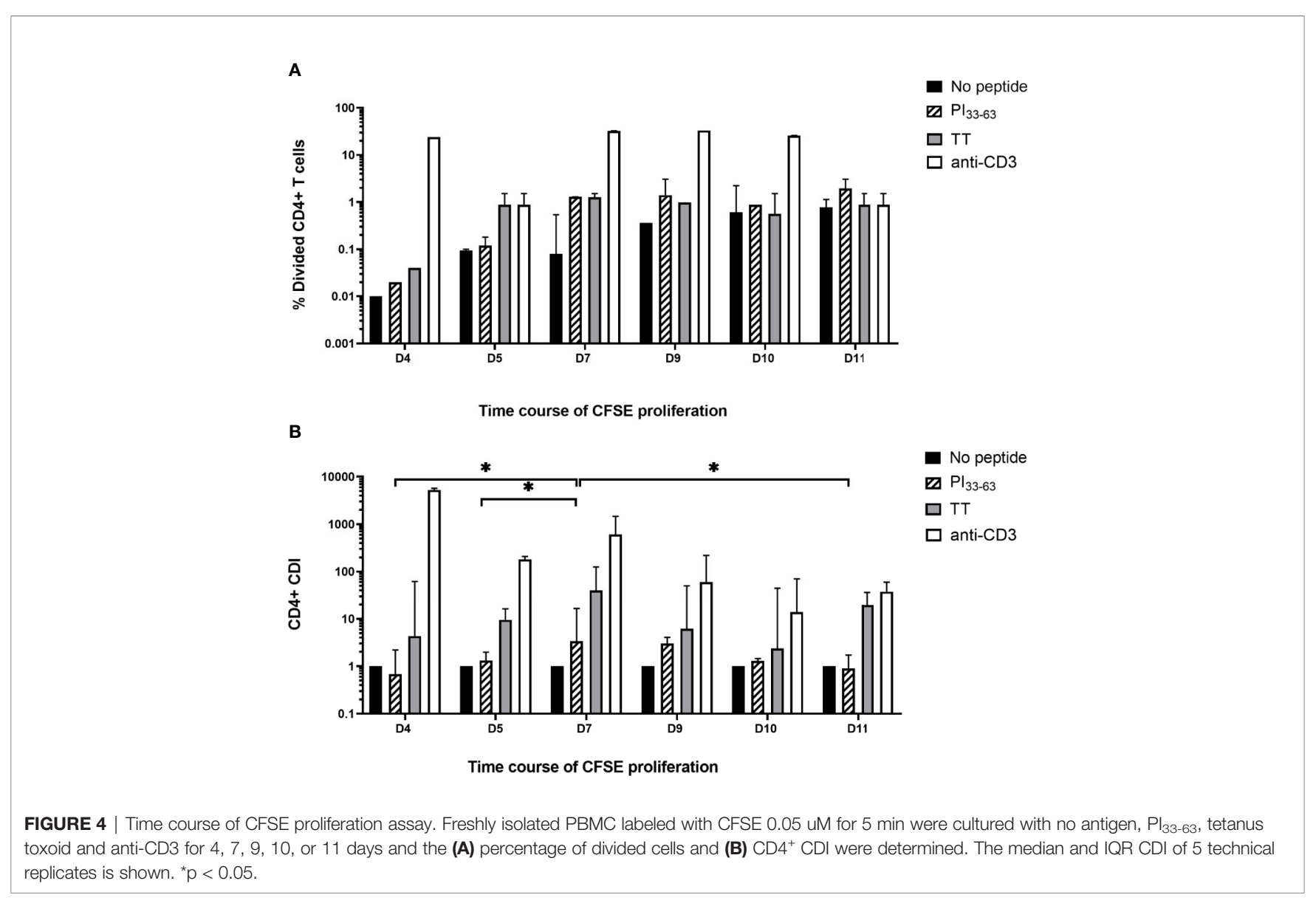



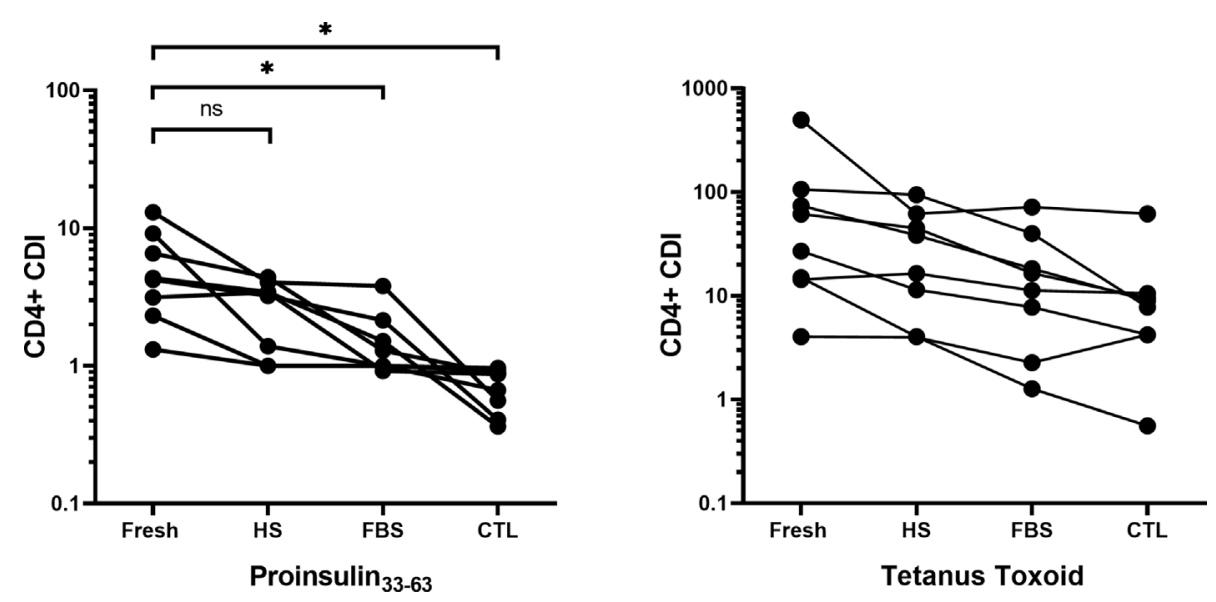

FIGURE 5 | Comparison of the CD4 ${ }^{+}$T-cell division index using freshly isolated PBMCs cryopreserved in FBS/10\% DMSO, HS/10\% DMSO or serum-free CTL media, measured with the CFSE-based T-cell proliferation assay for eight different patients. Seven days after cryopreservation, frozen PBMCs were thawed and incubated without peptide, or with $\mathrm{PI}_{33-63}$, tetanus toxoid or anti-CD3 antibody. CDI for each freezing media was compared to CDI for fresh PBMCs: ${ }^{\star} \mathrm{p}<0.05$ paired t test. Fresh, Freshly isolated PBMC; HS, Human Serum; FBS, Fetal Bovine Serum, CTL, CTL Cryo ${ }^{\text {TM }}$ solution ABC.

\section{DISCUSSION}

T-cell assays can be used as biomarkers to monitor immune responses that are crucial to validate the outcome of clinical studies. Such assays can be incorporated into biomarkers to define disease heterogeneity and to monitor the rate of disease progression. In order for T-cell biomarkers to achieve broad utility, the assays by which they are measured must shift from requiring specialized expertise into optimized and validated assays for widespread clinical application. The CFSE-based T-cell proliferation assay is a promising technique to measure antigenspecific T-cell proliferation (10). However, there are currently no guidelines standardizing CFSE-based antigen specific T-cell proliferation assays. Here, we addressed key assay parameters for detection of autoantigen $\mathrm{PI}_{33-63}$-specific $\mathrm{CD}^{+} \mathrm{T}$-cell proliferation in T1D. We demonstrate the importance of using objective gating parameters, selecting the ideal dye and its concentration, labeling time, the optimal harvest time of PBMCs after culture, storage time before PBMCs are processed and cryopreservation media.

Optimizing a fluorescent dye-based proliferative assay involves balancing between staining PBMCs as brightly and homogenously as possible, while maintaining cell viability and minimizing background fluorescence from no-peptide controls. Higher concentrations of CFSE increased signal intensity but were associated with higher cell toxicity. While higher CFSE concentrations decreased $\mathrm{PI}_{33-63^{-}}$ specific $\mathrm{CD}^{+} \mathrm{T}$-cell proliferation, reducing CFSE incubation times reduced background. Furthermore, we observed that different CFSE batches varied in staining intensity, impacting cell viability and proliferation in response to antigenic stimulation. Thus, CFSE titration studies should determine optimal concentration and staining time for labeling intensity and cell viability for each new batch of CFSE. For this reason, the current study employed the same batch of CFSE for all experiments in this paper. Other factors that minimized background proliferation and thereby increased the sensitivity of the assay included filtering human serum and meticulous attention to sterile technique. We demonstrated that minimizing the sample handling time prior to assay improves cell viability and antigen-specific proliferation. The sample storage period prior to processing reflected a time interval that can be feasibly implemented within a clinical research setting. We recognize that transit time, along with other factors such as changes in temperature, may affect cell viability and function and should be evaluated prior to implementation under other conditions.

Antigen-specific proliferation with the CFSE-based T-cell proliferation assay has mostly been tested using freshly isolated PBMCs. However, assays that use cryopreserved PBMCs are critical to investigate longitudinal changes in T-cell activity retrospectively. We observed that the cryopreservation medium influenced antigen-specific responses but that the CDIs obtained from PBMCs cryopreserved in HS were comparable to those of freshly isolated PBMCs. This was largely due to lower proliferation in the no-peptide control when using HS cryopreservation as compared to FBS cryopreservation where low-level proliferation could be induced by bovine-derived antigens present in FBS. Since cytokines and growth factors found in serum may influence lymphocyte responses (20), the use of a pooled large serum batch is preferable. Although previous studies suggested serum-free media reduces background events in no-peptide control wells in ELISPOT $(20,21)$, no such advantage was observed for the CFSE-based T-cell proliferation assay.

The capacity of cell permeant dyes such as CFSE to label lymphocyte populations with a high fluorescent intensity offers several advantages over ELISPOT. Proliferation assays enable more specific analysis of cell proliferation over several divisions. In addition, dividing cells can be characterized phenotypically 


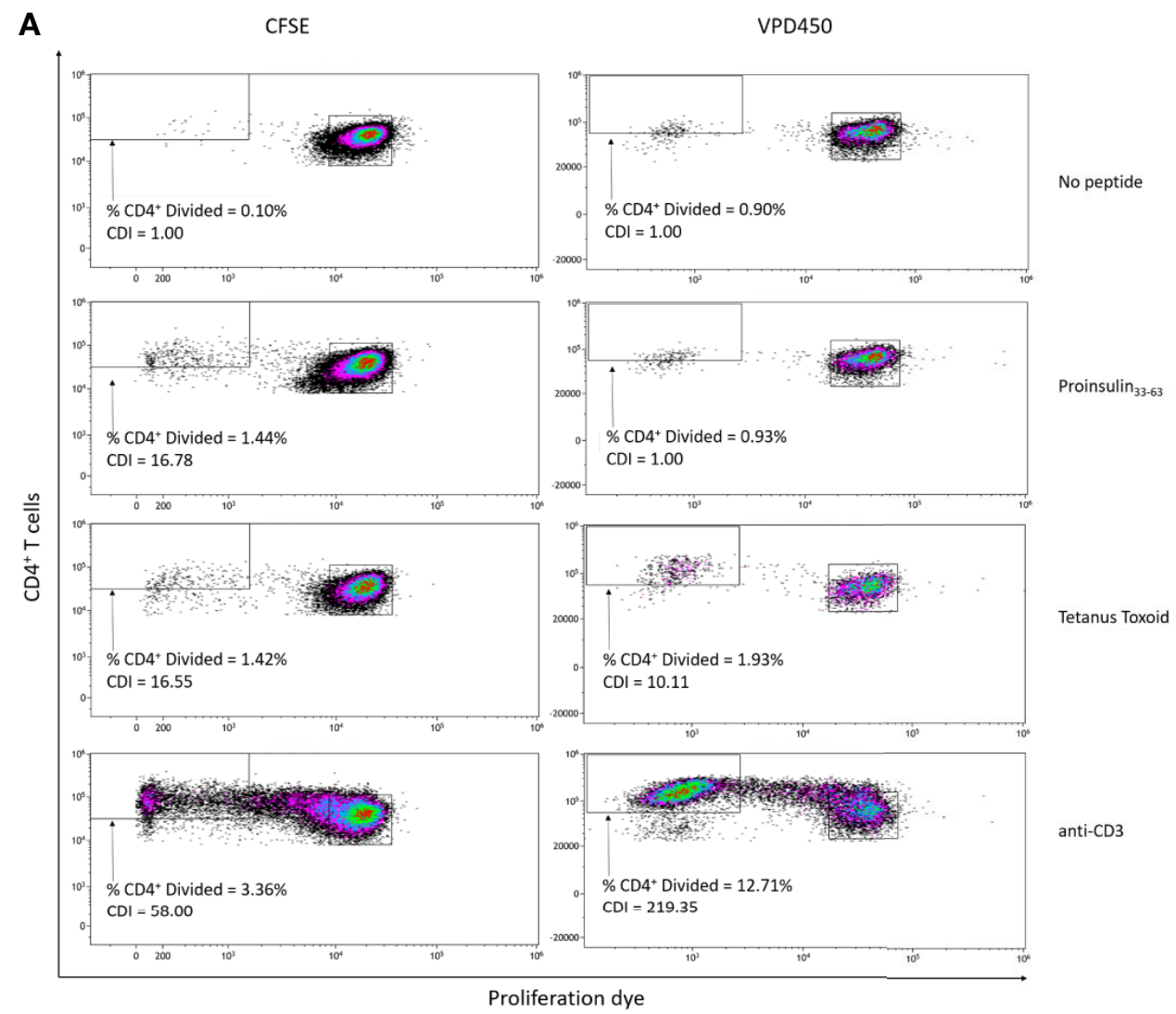

B

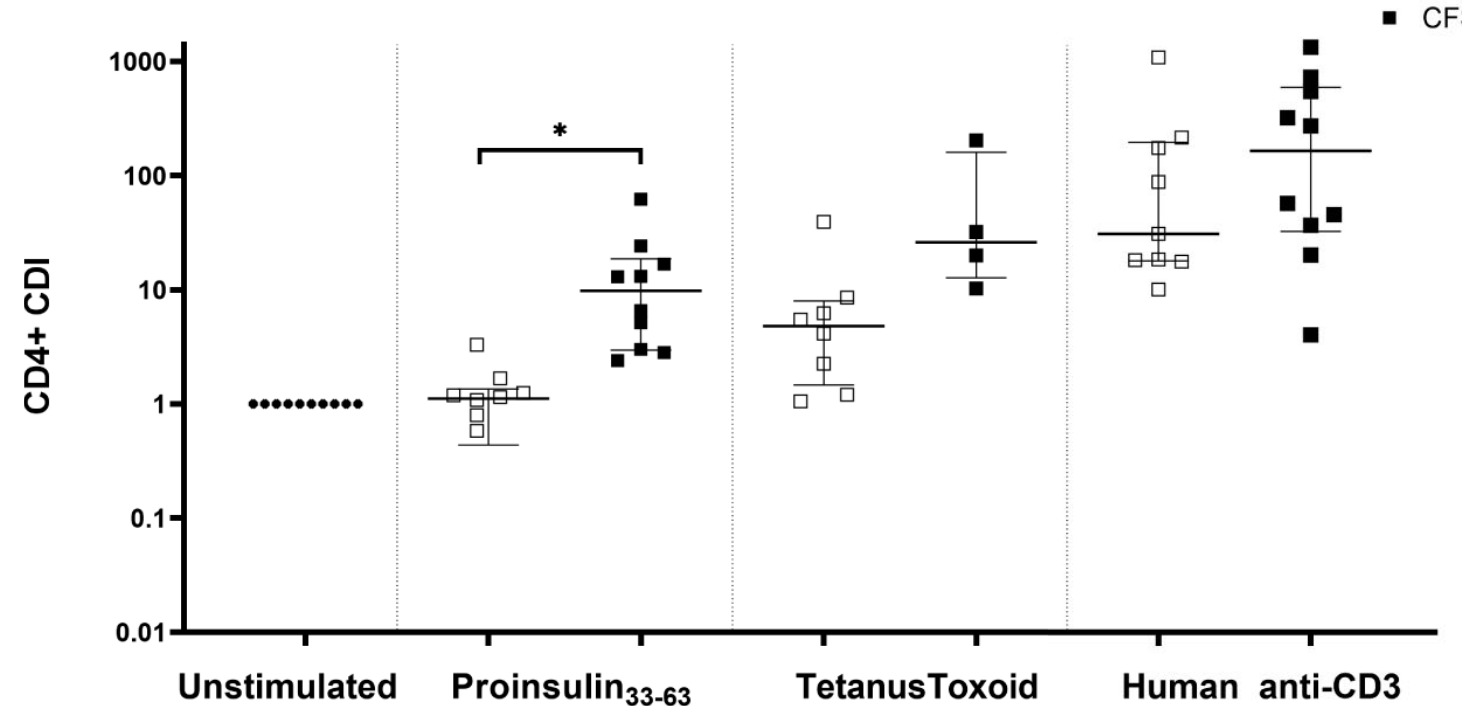

FIGURE 6 | Comparison of CFSE-based T-cell proliferation assay (concentration $0.05 \mu \mathrm{M}$, staining time $5 \mathrm{~min}$ ) and VPD450 assay (concentration $0.25 \mathrm{mM}$, staining time $15 \mathrm{~min}$ ) in freshly isolated PBMCs from subjects with T1D. (A) A representative patient in whom CDI was determined for CD4 ${ }^{+} \mathrm{T}$-cells in response to no antigen, $\mathrm{Pl}_{33-63}$, tetanus toxoid, and anti-CD3. (B) Combined data from 10 patients, each tested with VPD450 and CFSE-based T-cell proliferation assays. Each point represents a CDI from an individual patient. CDIs for no antigen, $\mathrm{Pl}_{33-63}$ and anti-CD3 are shown for all patients. CDIs for $T \mathrm{~T}$ were measured for 10/10 and 4/10 patients using the VPD450 and CFSE-based T-cell proliferation assay, respectively. Error bars display median \pm interquartile range. CDI for each CFSE-stained assay was compared to CDI for the corresponding VPD450-stained assay: ${ }^{\star} \mathrm{p}<0.05$ paired $\mathrm{t}$ test. 
A

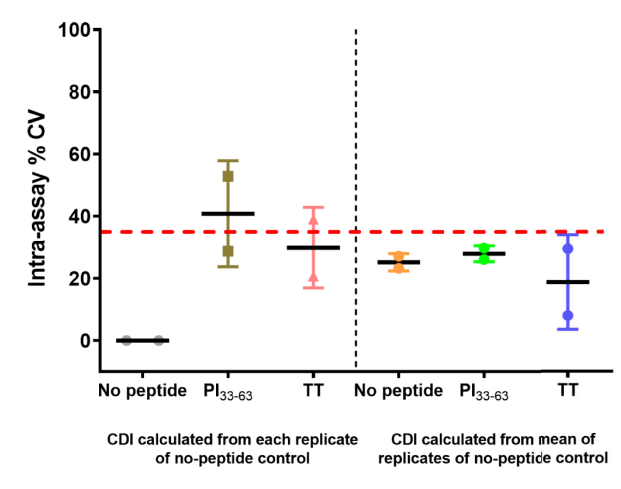

B

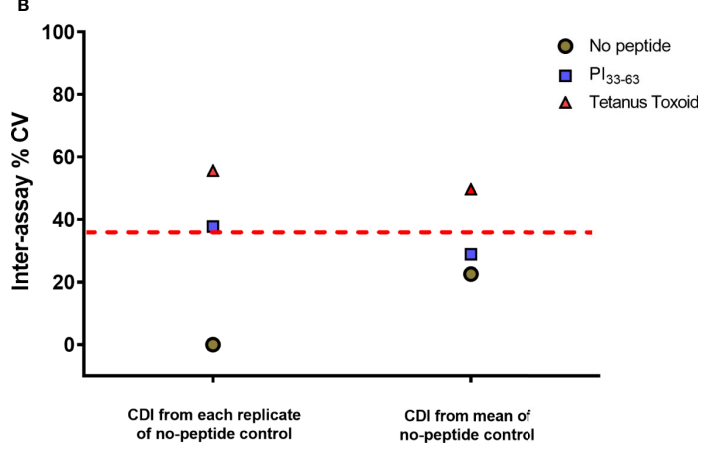

FIGURE 7 | $\mathrm{CD}^{+} \mathrm{CDI}$ to $\mathrm{Pl}_{33-63}$ and tetanus toxoid using cryopreserved PBMCs from a single patient with T1D $\leq 3$ months. Assays were performed independently by two analysts. The mean CDI of triplicate measurements was calculated and the \% Coefficient of Variation (CV) is shown. Each data point represents \% CV. The solid lines represent mean \% CV (intra-assay repeatability). The dashed red lines indicate the recommended threshold limit of $\mathrm{CV} \leq 35 \%$ (18). (A) Intra-assay repeatability for $\mathrm{CD}^{+}{ }^{+} \mathrm{T}$-cell proliferative responses within assays performed by two independent analysts. (B) Interassay reproducibility for $\mathrm{CD}^{+} \mathrm{T}$-cell proliferative responses between assays performed by two independent analysts.

using antibodies specific for surface markers and/or intracellular cytokines, which increases the information that can be obtained from a single functional assay. Since CFSE is a fluorescein-based dye it is also compatible with a broad range of other fluorochromes making it applicable to multi-color flow cytometry. In the case of ELISPOT assays, non-proliferating $\mathrm{T}$ cells or non-T cells may also produce cytokines, thus potentially reducing specificity of the assay to detect cytokine production from antigen-reactive $\mathrm{T}$ cells. CFSE also permits cloning of antigen-reactive cells via single-cell sorting. Thus, the scope and potential of the CFSE proliferation assay may exceed the output of the ELISPOT assay. When optimized, the CFSE proliferative assay is a sensitive means to detect antigenspecific proliferation.

To date, few comparative studies using alternative labeling dyes to CFSE have been conducted. We found that an assay based on CFSE was more sensitive in detecting antigen specific $\mathrm{CD}^{+}{ }^{+} \mathrm{T}$-cell proliferative responses using freshly isolated PBMCs than a VPD-450-based assay, due to higher background proliferation. While CFSE was superior toVPD450 in detecting $\mathrm{PI}_{33-63}$-specific $\mathrm{CD}^{+}{ }^{+} \mathrm{T}$-cell proliferation using our assay protocol, we did not attempt to further optimize parameters for VPD450, nor did we run trials with any other dye, such as cell trace violet (CTV). It is possible that further optimization of the VPD450-based T-cell proliferation assay, such as a reduction in labeling time, may have improved assay outputs. Alternatively, it is possible that issues with spectral overlap, whereby non-specific signal cannot be removed within the live/dead stain, resulted in a higher perceived VPD450 dilution in the unstimulated samples.

The reproducibility of $\mathrm{T}$-cell assays is dependent on the optimization and transferability of the assays that are used. The Immune tolerance Network and Type 1 Diabetes TrialNet have tested various antigen-specific T-cell based assays and have shown the highest sensitivity and specificity for an immunoblot assay and ELISpot measurements. However, these assays are yet to overcome the effects of sample preparation (e.g., freshly isolated PBMC versus frozen biosamples). Furthermore, immune response assays using pooled peptides for $\mathrm{T}$ cell stimulation may be unsuitable for measurement of antigenspecific $\mathrm{T}$ cell responses in clinical trials of antigen-specific immunotherapy (22). Attempts to validate the detection of antigen-specific $\mathrm{CD} 4^{+} \mathrm{T}$-cells with HLA class 1 multimers and class II tetramers demonstrated good reproducibility in individual laboratories but variable results across different laboratories $(23,24)$. As such, there are few widely usable, optimized assays for antigen-specific biomarkers in T1D.

We highlight the importance of the following critical parameters for reproducibility: recovery and viability of thawed PBMC, CFSE staining concentration and duration, standardized gating of divided cells, and pooled wells to improve numbers captured for flow cytometry analysis. Despite this, occasional nopeptide control wells had high cell division "noise". Therefore, running the assay in triplicate, and using mean of unstimulated proliferation to calculate CDI greatly improved intra-assay repeatability for the CDI value. We also noted reduced interassay reproducibility for the very high CDIs obtained after tetanus toxoid stimulation. This may have resulted from small variations in the tetanus toxoid CFSE dilution profile between analysts, due to small differences in pipetting CFSE at assay setup, which are amplified over a 7-day CFSE dilution assay. This variability can be overcome when a single analyst runs the assay, which would allow comparison of CDI over time or to different antigens in a clinical trial.

Here, we have systematically optimized and qualified a CFSEbased $\mathrm{T}$-cell proliferation assay targeting rare antigen-specific $\mathrm{CD}^{+} \mathrm{T}$-cells in children with T1D $(10,25)$. Toward the goal of establishing a fit-for-purpose assay, we have made every effort to comply with recognized standards of validation. The importance of strict attention to assay and analysis parameters has been highlighted, providing a protocol to allow harmonization across different laboratories. An advantage of this assay is the potential for the inclusion of phenotypic and functional determinations (26). Although it is known that T-cells are essential constituents of T1D disease progression, their phenotype is yet to be fully 


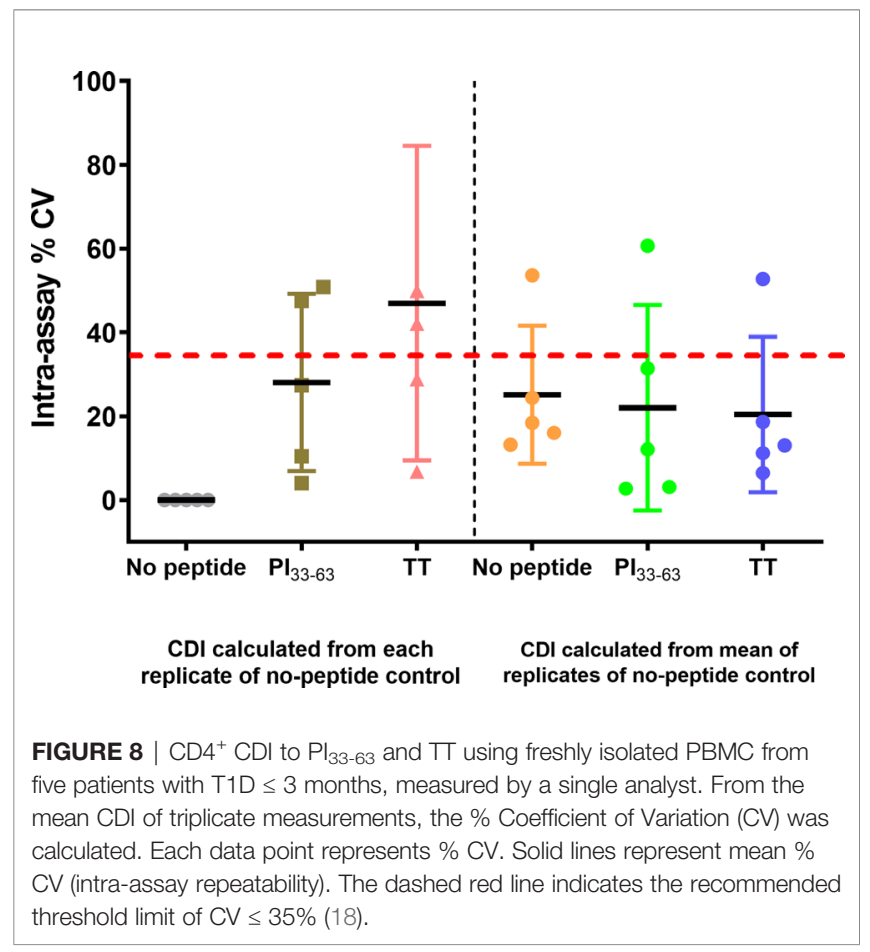

evaluated. Future efforts will be able to facilitate an integration of optimized flow cytometric approaches with newer technologies to create T-cell biomarkers that have single-cell resolution. For example, the CFSE-based proliferation assay can be paired with platforms such as multi-parameter cytometry (27) in order to phenotype an array of surface and intracellular markers. Transcriptomic and TCR analyses $(28,29)$ can incorporate single-cell approaches to shed light on pathogenic signatures or mechanisms underlying disease. Together these assays should enhance understanding of the immunogenic mechanisms underpinning T1D and the response to novel immunemodulatory agents.

\section{DATA AVAILABILITY STATEMENT}

The original contributions presented in the study are included in the article/Supplementary Material. Further inquiries can be directed to the corresponding author.

\section{REFERENCES}

1. Babon JAB, DeNicola ME, Blodgett DM, Crèvecoeur I, Buttrick TS, Maehr R, et al. Analysis of self-antigen specificity of islet-infiltrating $\mathrm{T}$ cells from human donors with type 1 diabetes. Nat Med (2016) 22(12):1482-7. doi: 10.1038/ nm. 4203

2. Atkinson MA, von Herrath M, Powers AC, Clare-Salzler M. Current Concepts on the Pathogenesis of Type 1 Diabetes-Considerations for Attempts to Prevent and Reverse the Disease. Diabetes Care (2015) 38 (6):979-88. doi: $10.2337 / \mathrm{dc} 15-0144$

\section{ETHICS STATEMENT}

The studies involving human participants were reviewed and approved by Children's Health Queensland, Mater Hospital and University of Queensland Human Research Ethics Committees. Written informed consent to participate in this study was provided by the participants' legal guardian/next of kin.

\section{AUTHOR CONTRIBUTIONS}

YM, SP, HN, EH-W, MH, and RT designed research. YM, HN, and NR performed research. YM, HN, EH-W, SP, MH, and RT analyzed data. YM, HN, NR, SP, EH-W, MH, and RT prepared the manuscript. All authors contributed to the article and approved the submitted version.

\section{FUNDING}

This work was supported by a grant from The Leona M. and Harry B. Helmsley Charitable Trust and Juvenile Diabetes Research Foundation Australia to RT, MH, and EH-W. RT is supported by Arthritis Queensland and an NHMRC Research Fellowship. YM is supported by a University of Queensland Post-Graduate Award, Pfizer Australasian Paediatric Endocrine Care Grant, Butta Clinician Researcher Bursary, Children's Health Foundation PhD Top up Scholarship, Royal Australasian College of Physicians Foundation Development and Research Entry Scholarship.

\section{ACKNOWLEDGMENTS}

We thank Nicholas Mattigan for statistical advice. We thank Stuart Mannering and Michelle So for guidance around laboratory methods and Nathan Stone for laboratory assistance. We thank David Sester, Yitian Ding, and Dalia Khalil for the services provided by the Translational Research Institute Flow Cytometry Core Suite. We are immensely grateful to the children and families who contributed to this research.

\section{SUPPLEMENTARY MATERIAL}

The Supplementary Material for this article can be found online at: https://www.frontiersin.org/articles/10.3389/fimmu.2020. 587469/full\#supplementary-material

3. Krishnamurthy B, Dudek NL, McKenzie MD, Purcell AW, Brooks AG, Gellert S, et al. Responses against islet antigens in NOD mice are prevented by tolerance to proinsulin but not IGRP. J Clin Invest (2006) 116(12):3258-65. doi: 10.1172/JCI29602

4. Vendrame F, Pileggi A, Laughlin E, Allende G, Martin-Pagola A, Molano RD, et al. Recurrence of Type 1 Diabetes After Simultaneous Pancreas-Kidney Transplantation, Despite Immunosuppression, Is Associated With Autoantibodies and Pathogenic Autoreactive CD4 T-Cells. Diabetes (2010) 59(4):947-57. doi: 10.2337/db09-0498

5. Pathiraja V, Kuehlich JP, Campbell PD, Krishnamurthy B, Loudovaris T, Coates PTH, et al. Proinsulin-specific, HLA-DQ8, and HLA-DQ8- 
transdimer-restricted CD4+T cells infiltrate islets in type 1 diabetes. Diabetes (2015) 64(1):172-82. doi: 10.2337/db14-0858

6. Delong T, Wiles TA, Baker RL, Bradley B, Barbour G, Reisdorph R, et al. Pathogenic CD4 $\mathrm{T}$ cells in type 1 diabetes recognize epitopes formed by peptide fusion. Science (80-) (2016) 351(6274):711-4. doi: 10.1126/ science.aad2791

7. Seyfert-Margolis V, Gisler TD, Asare AL, Wang RS, Dosch HM, BrooksWorrell B, et al. Analysis of T-cell assays to measure autoimmune responses in subjects with type 1 diabetes: Results of a blinded controlled study. Diabetes (2006) 55(9):2588-94. doi: 10.2337/db05-1378

8. Nepom GT. MHC multimers: expanding the clinical toolkit. Clin Immunol (2003) 106(1):1-4. doi: 10.1016/S1521-6616(02)00014-1

9. Mannering SI, Wong FS, Durinovic-Belló I, Brooks-Worrell B, Tree TI, Cilio $\mathrm{CM}$, et al. Current approaches to measuring human islet-antigen specific T cell function in type 1 diabetes. Clin Exp Immunol (2010) 162(2):197-209. doi: $10.1111 / j .1365-2249.2010 .04237 . x$

10. Mannering SI, Morris JS, Jensen KP, Purcell AW, Honeyman MC, van Endert $\mathrm{PM}$, et al. A sensitive method for detecting proliferation of rare autoantigenspecific human T cells. J Immunol Methods (2003) 283(1-2):173-83. doi: 10.1016/j.jim.2003.09.004

11. Ten Brinke A, Marek-Trzonkowska N, Mansilla MJ, Turksma AW, Piekarska K, Iwaszkiewicz-Grześ D, et al. Monitoring T-Cell Responses in Translational Studies: Optimization of Dye-Based Proliferation Assay for Evaluation of Antigen-Specific Responses. Front Immunol (2017) 8:1870. doi: 10.3389/fimmu.2017.01870

12. Mannering SI, Dromey JA, Morris JS, Thearle DJ, Jensen KP, Harrison LC. An efficient method for cloning human autoantigen-specific T cells. J Immunol Methods (2005) 298(1-2):83-92. doi: 10.1016/j.jim.2005.01.001

13. Nomura L, Maino VC, Maecker HT. Standardization and optimization of multiparameter intracellular cytokine staining. Cytom Part A (2008) 73 (11):984-91. doi: 10.1002/cyto.a.20602

14. Mallone R, Kochik SA, Reijonen H, Carson B, Ziegler SF, Kwok WW, et al. Functional avidity directs T-cell fate in autoreactive CD4+ T cells. Blood (2005) 106(8):2798-805. doi: 10.1182/blood-2004-12-4848

15. Bulek AM, Cole DK, Skowera A, Dolton G, Gras S, Madura F, et al. Structural basis for the killing of human beta cells by CD8+ T cells in type 1 diabetes. Nat Immunol (2012) 13(3):283-9. doi: 10.1038/ni.2206

16. So M, Elso CM, Tresoldi E, Pakusch M, Pathiraja V, Wentworth JM, et al. Proinsulin C-peptide is an autoantigen in people with type 1 diabetes. Proc Natl Acad Sci U S A (2018) 115(42):10732-7. doi: 10.1073/pnas.1809208115

17. American Diabetes Association AD. (2) Classification and diagnosis of diabetes. Diabetes Care (2015) 38 Suppl(Supplement 1):S8-16. doi: 10.2337/ dc15-S005

18. Selliah N, Eck S, Green C, Oldaker T, Stewart J, Vitaliti A, et al. Flow Cytometry Method Validation Protocols. Curr Protoc Cytom (2019) 87(1):e53. doi: $10.1002 /$ cpcy. 53

19. Rohrer J, Elia J, Rabenstein J. Optimization of loading conditions for a violet dye for use in cell proliferation studies (65.9). J Immunol (2011) 186(1 Supplement).

20. Germann A, Schulz JC, Kemp-Kamke B, Zimmermann H, Von Briesen H. Standardized serum-free cryomedia maintain peripheral blood mononuclear cell viability, recovery, and antigen-specific T-cell response compared to fetal calf serum-based medium. Biopreserv Biobank (2011) 9(3):229-36. doi: 10.1089/bio.2010.0033

21. Filbert H, Attig S, Bidmon N, Renard BY, Janetzki S, Sahin U, et al. Serum-free freezing media support high cell quality and excellent ELISPOT assay performance across a wide variety of different assay protocols. Cancer Immunol Immunother (2013) 62(4):615-27. doi: 10.1007/s00262-012-1359-5

22. Yang J, Wen X, Xu H, Torres-Chinn N, Speake C, Greenbaum CJ, et al. Antigen-Specific T Cell Analysis Reveals That Active Immune Responses to $\beta$ Cell Antigens Are Focused on a Unique Set of Epitopes. J Immunol (2017) 199 (1):91-6. doi: 10.4049/jimmunol.1601570

23. James EA, Mallone R, Schloot NC, Gagnerault MC, Thorpe J, FitzgeraldMiller L, et al. Immunology of diabetes society T-cell workshop: HLA class II tetramer-directed epitope validation initiative. Diabetes Metab Res Rev (2011) 27(8):727-36. doi: 10.1002/dmrr.1244

24. Brooks-Worrell B, Tree T, Mannering SI, Durinovic-Bello I, James E, Gottlieb $\mathrm{P}$, et al. Comparison of cryopreservation methods on T-cell responses to islet and control antigens from type 1 diabetic patients and controls. Diabetes Metab Res Rev (2011) 27(8):737-45. doi: 10.1002/dmrr.1245

25. Mannering SI, Harrison LC, Williamson NA, Morris JS, Thearle DJ, Jensen $\mathrm{KP}$, et al. The insulin A-chain epitope recognized by human $\mathrm{T}$ cells is posttranslationally modified. J Exp Med (2005) 202(9):1191-7. doi: 10.1084/ jem. 20051251

26. Turcanu V, Maleki SJ, Lack G. Characterization of lymphocyte responses to peanuts in normal children, peanut-allergic children, and allergic children who acquired tolerance to peanuts. J Clin Invest (2003) 111(7):1065-72. doi: $10.1172 / J C I 200316142$

27. Laban S, Suwandi JS, Van Unen V, Pool J, Wesselius J, Höllt T, et al. Heterogeneity of circulating CD8 T-cells specific to islet, neo-antigen and virus in patients with type 1 diabetes mellitus. PLoS One (2018) 13(8): e0200818. doi: 10.1371/journal.pone.0200818

28. Heninger AK, Eugster A, Kuehn D, Buettner F, Kuhn M, Lindner A, et al. A divergent population of autoantigen-responsive CD4+ T cells in infants prior to b cell autoimmunity. Sci Transl Med (2017) 9(378):eaaf8848. doi: 10.1126/ scitranslmed.aaf8848

29. Cerosaletti K, Barahmand-pour-Whitman F, Yang J, DeBerg HA, Dufort MJ, Murray SA, et al. Single-Cell RNA Sequencing Reveals Expanded Clones of Islet Antigen-Reactive CD4 + T Cells in Peripheral Blood of Subjects with Type 1 Diabetes. J Immunol (2017) 199(1):323-35. doi: 10.4049/ jimmunol.1700172

Conflict of Interest: The authors declare that the research was conducted in the absence of any commercial or financial relationships that could be construed as a potential conflict of interest.

Copyright (๑) 2020 Musthaffa, Nel, Ramnoruth, Patel, Hamilton-Williams, Harris and Thomas. This is an open-access article distributed under the terms of the Creative Commons Attribution License (CC BY). The use, distribution or reproduction in other forums is permitted, provided the original author(s) and the copyright owner(s) are credited and that the original publication in this journal is cited, in accordance with accepted academic practice. No use, distribution or reproduction is permitted which does not comply with these terms. 